\title{
Intact Hedonic Responses to Sweet Tastes in Autism Spectrum Disorder
}

\author{
Cara R. Damiano ${ }^{a,{ }^{*}}$, Joseph Aloi ${ }^{\mathrm{a}}$, Caley Burrus ${ }^{\mathrm{b}}$, James C. Garbutt ${ }^{\mathrm{c}, \mathrm{d}}$, Alexei B. Kampov- \\ Polevoy ${ }^{\mathrm{c}, \mathrm{d}}$, and Gabriel S. Dichter ${ }^{\mathrm{a}, \mathrm{d}, \mathrm{e}}$ \\ a Department of Psychology, University of North Carolina at Chapel Hill, CB\#3270, Davie Hall, \\ Chapel Hill, NC, 27599-3270, USA. \\ b Department of Psychology and Neuroscience, Duke University, Durham, NC 27705 \\ c Bowles Center for Alcohol Studies, University of North Carolina School of Medicine, CB\# 7160, \\ Chapel Hill, NC, 27599, USA. \\ d Department of Psychiatry, University of North Carolina at Chapel Hill School of Medicine, CB\# \\ 7160, Chapel Hill, NC 27599-7160, USA. \\ e Carolina Institute for Developmental Disabilities, University of North Carolina School of \\ Medicine, CB\# 7255, 101 Manning Drive, Chapel Hill, NC 27599, USA.
}

\begin{abstract}
The Sweet Taste Test (STT) is a standardized measure designed to index the ability to detect differences in sweet tastes (sweet taste sensitivity) and hedonic responses to sweet tastes (sweet taste liking). Profiles of response on the STT suggest enhanced hedonic responses to sweet tastes in psychiatric disorders characterized by dysfunctional reward processing systems, including binge-eating disorders and substance use disorders, and a putative mechanism governing STT responses is the brain opioid system. The present study examined STT responses in 20 adults with autism spectrum disorder (ASD) and 38 healthy control adults. There were no differences in sweet taste sensitivity or hedonic response to sweet tastes between the ASD and control groups. Within the ASD sample, ASD symptom severity was associated with sweet taste sensitivity, but not hedonic response to sweet taste. Results may ultimately shed light on brain opioid system functioning in ASD.
\end{abstract}

\section{Keywords}

autism spectrum disorder (ASD); reward processing; sweet taste; opioid system; primary rewards

\footnotetext{
(c) 2013 Elsevier Ltd. All rights reserved.

*Address correspondence to: Cara Damiano, Department of Psychology, CB\#3270, Davie Hall, UNC-CH, Chapel Hill, NC, 27599 , Phone: 314-882-0581, Fax Number: 919-869-2990, cdamiano@email.unc.edu..

Author Email Addresses: Joseph Aloi: aloijm@gmail.com Caley Burrus: cjb53@duke.edu James C. Garbutt:

JC_Garbutt@med.unc.edu Alexei B. Kampov-Polevoy: alexei_kampov-polevoi@med.unc.edu Gabriel S. Dichter: dichter@med.unc.edu

Publisher's Disclaimer: This is a PDF file of an unedited manuscript that has been accepted for publication. As a service to our customers we are providing this early version of the manuscript. The manuscript will undergo copyediting, typesetting, and review of the resulting proof before it is published in its final citable form. Please note that during the production process errors may be discovered which could affect the content, and all legal disclaimers that apply to the journal pertain.
} 


\section{Introduction}

Autism spectrum disorder (ASD) is characterized by social communication impairments and restricted and repetitive behaviors and interests (APA, 2013). Despite the heterogeneity of symptom presentation in ASD, impaired reward-based processes have been proposed as a possible core deficit (Dawson et al., 2004; Dawson, Webb, \& McPartland, 2005; Grelotti, Gauthier, \& Schultz, 2002). Consistent with this conceptualization, there is emerging evidence for atypical reward processing of both social and nonsocial rewards in ASD across both behavioral and neurobiologic domains (e.g., Cascio et al., 2012; Damiano, Aloi, Treadway, Bodfish, \& Dichter, 2012; Delmonte et al., 2012; Dichter, Richey, Rittenberg, Sabatino, \& Bodfish, 2012).

Reward processing may be decomposed into a number of distinct constructs mediated by distinguishable neurobiological mechanisms, including the anticipation of rewards (i.e., reward "wanting" or motivation towards future rewards) and the experience of obtaining rewards (i.e., reward "liking" or reward consumption; Berridge \& Robinson, 2003; Kringelbach \& Berridge, 2009). Amongst studies that have examined these two components of reward processing separately, there is considerable evidence for impairments in reward "wanting" in ASD, (for review, see Dichter, Damiano, \& Allen, 2012). However, evidence for impairments in reward consumption or "liking" in ASD is less consistent (Kohls, Chevallier, Troiani, \& Schultz, 2012). Indeed, these constructs are neurobiologically distinct: , reward "wanting" is associated with mesolimbic dopaminergic brain circuitry, and reward "liking" is mediated by a medial prefrontal cortical network that is heavily innervated by neural opioid systems (Barbano \& Cador, 2007; Berridge \& Kringelbach, 2011).

Studies of reward processing in ASD to date have relied primarily on paradigms involving the presentation of visual stimuli (i.e., images representing monetary values or images of social or non-social rewards) which are secondary rewards and thus suboptimal for assessing hedonic "liking" responses. Notably, no study to date has directly examined responses to primary rewards in ASD. The current study sought to address this gap in the literature by investigating hedonic responses to sweet tastes in ASD.

Hedonic responses to sweet tastes are heritable and relatively stable across time and changes in metabolic state (Keskitalo et al., 2007; Looy \& Weingarten, 1991; Mennella, Pepino, \& Reed, 2005; Thompson, Moskowitz, \& Campbell, 1976). A tendency to prefer more concentrated sweet solutions has been found across several different forms of psychopathology characterized by dysfunctional reward processing, including eating disorders and substance use disorders (Kampov-Polevoy, Eick, Boland, Khalitov, \& Crews, 2006; Kampov-Polevoy, Garbutt, Davis, \& Janowsky, 2006; Kampov-Polevoy, Tsoi, Zvartau, Neznanov, \& Khalitov, 2001; Kampov-Polevoy, Ziedonis, et al., 2006; Krahn et al., 2006; Wronski et al., 2007). The processing of sweet taste involves two distinct neural pathways: (1) a taste detection/discrimination pathway extending from the thalamus to the primary gustatory cortex, and (2) a taste hedonic processing pathway extending from the thalamus to the limbic system and other reward-related brain regions (Hajnal \& Norgren, 2005; Kosar, Grill, \& Norgren, 1986; Reilly, Grigson, \& Norgren, 1993). This second pathway is centrally involved in sweet taste liking (Pecina \& Berridge, 2005; Pecina, Smith, $\&$ Berridge, 2006) and is linked to endogenous levels of brain opioids (Calcagnetti \& Reid, 1983; Garbutt et al., 2009; Leventhal \& Bodnar, 1996; Miller, Barr, \& Young, 1994; Pecina \& Berridge, 2005; Pepino \& Mennella, 2005). Specifically, brain opioids regulate sweet taste liking, sensitivity to the mood altering effects of sweet tastes, and coding for the valence of rewards more broadly (Berridge \& Robinson, 1998; Kampov-Polevoy, Alterman, Khalitov, \& Garbutt, 2006; Smith \& Berridge, 2007). In this regard, hedonic response to 
sweet tastes is a marker of opioid functioning related to the hedonic processing of a primary reward.

The purpose of the current study was to investigate potential differences between individuals with ASD and controls in sweet taste sensitivity and sweet taste liking, as well as to examine associations between these measures and ASD symptom severity. These constructs were indexed using a standardized measure of sweet taste sensitivity and liking, the Sweet Taste Test (STT), which has been used extensively in previous studies of both clinical and nonclinical populations (e.g., Dichter, Smoski, Kampov-Polevoy, Gallop, \& Garbutt, 2010; Kampov-Polevoy, Garbutt, et al., 2006; Lange, Kampov-Polevoy, \& Garbutt, 2010). Given the growing literature on reward processing in ASD and evidence that perception of sweet tastes is intact in ASD (Bennetto, Kuschner, \& Hyman, 2007), we hypothesized that the ASD group would not differ in sensitivity to sweet tastes but only in sweet liking (i.e., the hedonic response to sweet tastes) and that, within the ASD group, sweet liking would be related to ASD symptom severity.

\section{Method}

\subsection{Participants}

The ASD group included 21 adults with ASD diagnoses provided by experienced licensed clinicians and confirmed with the Autism Diagnostic Observation Schedule-Generic (ADOS-G) using standard clinical cutoffs (Lord et al., 2000). The ADOS-G is a semistructured observational assessment used to evaluate symptoms of ASD across five behavioral domains: Language and Communication, Reciprocal Social Interaction, Play or Imagination/Creativity, Stereotyped Behaviors and Restricted Interests, and Other Abnormal Behaviors. The ADOS-G has demonstrated strong psychometric properties, including good test-retest reliability, interrater reliability, and internal consistency (Lord et al., 2000). Participants in the ASD group were recruited via an ASD research registry maintained by the Carolina Institute for Developmental Disabilities. The control group included 40 adults without ASD recruited from databases of undergraduate students participating in research for course credit and from databases of control participants maintained by the Duke-UNC Brain Imaging and Analysis Center. All participants had IQ scores 285 on the Wechsler Abbreviated Scale of Intelligence (WASI; Wechsler, 1999) and no known sensory deficits. The data from three control participants and one participant with ASD were discarded due to missing data, resulting in final samples of 20 participants with ASD (three females, 17 males) and 37 control participants (four female, 33 males). The final ASD group was $85 \%$ Caucasian, 10\% African-American, and 5\% Asian, and the control group was 78.4\% Caucasian, 8.1\% African-American, 8.1\% Asian, 2.7\% Native American, and 2.7\% Hispanic. All participants provided written informed consent.

Groups did not differ in Verbal, Performance, or Full Scale IQ, all $p$ 's > .10 (see Table 1). In addition, groups did not differ in gender or race/ethnicity distributions, all $p$ 's $>.10$. However, ASD participants were significantly older on average $(M=25.95, S D=7.96)$ than control participants $(M=20.42, S D=5.64), t$-test for unequal variance: $t(29.31)=2.76, p=$. 01 . Thus between-groups analyses were conducted both with and without age as a covariate.

\subsection{Sweet Taste Test (STT)}

The STT is a standardized measure of response to sweet tastes, which requires participants to taste five concentrations of sucrose solutions (.05M, .10M, .21M, .42M, and $.83 \mathrm{M})$. As a comparison, Coca-Cola ${ }^{\circledR}$ is a $0.33 \mathrm{M}$ solution. All participants were blinded to the sucrose concentration of each solution and the solutions were presented in a pseudo-randomized order. Participants completed five trials with each solution ( 25 trials in total) and were 
instructed to sip each solution, swish it around in their mouths, and spit it out. Immediately after each taste, participants provided ratings of sweet sensitivity ("How sweet was the taste?") and sweet liking ("How much did you like the taste?") by marking a horizontal line on a $200 \mathrm{~mm}$ analog scale. For sweet sensitivity ratings, the leftmost end of the line indicated a response of "Not sweet at all" and the rightmost end indicated a response of "Extremely sweet." For the sweet liking ratings, the leftmost end indicated a response of "Disliked very much" and the rightmost end indicated a response of "Liked very much". Participants rinsed their mouths using distilled water between each taste.

\subsection{Measures of ASD Symptomatology}

Autism symptomatology was indexed through the Social Responsiveness Scale (SRS; Constantino et al., 2003) and the Autism Spectrum Quotient questionnaire (AQ; BaronCohen, Wheelwright, Skinner, Martin, \& Clubley, 2001). The AQ and the SRS are both selfreport measures designed to provide quantitative measures of traits related to ASD across populations with and without a diagnosis of ASD. The SRS is a 65-item questionnaire on which participants rate statements on a four-point Likert Scale (ranging from "not true" to "almost always true"). The SRS has demonstrated good test-retest reliability, cross-cultural validity, and convergent and divergent validity (Bölte, Poustka, \& Constantino, 2008; Constantino et al., 2003; Constantino, Przybeck, Friesen, \& Todd, 2000). The AQ is a 50item questionnaire on which participants rate the extent to which they agree with a statement on a 4-point Likert scale. The AQ has demonstrated good test-retest reliability, internal consistency, and cross-cultural validity (Baron-Cohen et al., 2001; Hoekstra, Bartels, Cath, \& Boomsma, 2008; Kurita, Koyama, \& Osada, 2005). On both measures, higher scores indicate a greater severity of ASD symptomatology.

\subsection{Data Reduction and Statistical Analyses}

Data were analyzed using the same standardized methods as previous studies involving the STT to allow for comparability across studies (Dichter et al., 2010; Garbutt et al., 2009; Kampov-Polevoy, Alterman, et al., 2006; Kampov-Polevoy, Eick, Boland, Khalitov, \& Crews, 2004; Kampov-Polevoy, Garbutt, \& Khalitov, 2003; Kampov-Polevoy, Ziedonis, et al., 2006). Consistent with these previous studies utilizing the STT, three dependent measures were derived: (1) sensitivity to sucrose, indexed by the slope of sucrose concentration by sweet sensitivity ratings; (2) hedonic response, indexed by the slope of sucrose concentration by sweet liking ratings; and (3) binary classification of individuals as "sweet likers" or "sweet dislikers" based on sweet liking ratings.

First, the length (in $\mathrm{mm}$ ) was measured from the leftmost end of the line to the horizontal lines for each rating of "How sweet was the taste?" (sweet sensitivity) and "How much did you like the taste?" (sweet liking). Raw scores were then averaged across each of the five trials completed for each solution and a natural logarithm transformation was applied to these averaged raw scores. Primary analyses focused on group differences in the slopes for sweet liking and "sweet liker" vs. "sweet disliker" classifications, both of which have been shown to be stable traits (Greenfield, Trucco, McHugh, Lincoln, \& Gallop, 2007) and linked to brain opioid functioning (Garbutt et al., 2009). Sensitivity to sweetness ratings addressed whether groups differed in the perception of different levels of sucrose, a trait that is relatively independent of brain opioid functioning (Arbisi, Billington, \& Levine, 1999; Frisina \& Sclafani, 2002; Hetherington, Vervaet, Blass, \& Rolls, 1991; O'Hare et al., 1997; Yeomans \& Gray, 1996).

For the slope measures, higher values denoted greater sensitivity to sweetness (for sweet sensitivity ratings) or greater hedonic response (for sweet liking ratings) as sweet concentrations increased. These slope measures were submitted to general linear models to 
compare groups (with and without covariation for age), using partial eta-squared effect sizes $(\eta 2 ; 0.01=$ small, $0.06=$ medium, $0.14=$ large; Cohen, 1973). For the "sweet likers" versus "sweet dislikers" classifications, a "sweet liker" was defined as an individual who rated the highest sucrose concentration $(0.83 \mathrm{M})$ as the most preferred solution, whereas a "sweet disliker" preferred lower sucrose concentrations $(0.05,0.10,0.21$, or $0.42 \mathrm{M})$. A chi-square analysis was used to compare groups on these classifications and the effect size was calculated using an odds ratio (1.5 = small, 2.5 = medium, $4=$ large; Rosenthal, 1996). Finally, correlations were conducted to examine potential relations between STT measures and ASD severity within the ASD group, assessed by the Social Responsiveness Scale (SRS; Constantino et al., 2003) and the Autism Spectrum Quotient questionnaire (AQ; Baron-Cohen et al., 2001). Due to the exploratory nature of these STT-symptom correlations, they were not corrected for multiple comparisons.

\section{Results}

\subsection{Sweet sensitivity}

No significant differences between groups were found for slopes related to sweet sensitivity, $F(1,55)=0.09, p=.77, \eta^{2}=.002$. This analysis was also not significant when age was covaried, $F(1,54)=0.85, p=.43, \eta^{2}=.030$. Table 2 displays the raw score rating means and standard deviations for sweet sensitivity, which illustrate that the means and variability of the ratings were comparable for the ASD and control groups. A direct comparison of the raw average sweet sensitivity ratings for the ASD versus the control group also revealed no significant difference for this measure, $F(1,55)=0.28, p=.60$.

\subsection{Sweet liking}

No significant differences between the ASD and control groups were found for slopes related to hedonic response $F(1,55)=1.09, p=.30, \eta^{2}=.019$. This analysis was also not significant when age was covaried, $F(1,54)=0.67, p=.52, \eta^{2}=.024$. As displayed in Table 2 , the means and standard deviations for the raw score sweet liking ratings were comparable for the ASD versus control groups. A direct comparison of the raw average sweet sensitivity ratings for the ASD versus the control group also revealed no significant difference for this measure, $F(1,55)=0.006, p=.94$.

\subsection{Sweet liker versus sweet disliker classification}

Similarly, no significant differences between the ASD and control groups were found in the proportion of sweet likers vs. sweet dislikers, $\chi=1.03, p=.31$, odds ratio $=0.57$. The control group was composed of 20 sweet likers ( $54 \%$ of the control sample) and 17 sweet dislikers ( $\sim 46 \%)$. The ASD group was composed of 8 sweet likers (40\%) and 12 sweet dislikers $(60 \%)$.

\subsection{Relations to ASD Symptoms}

Within the ASD group, SRS $t$-scores were negatively related to sweet sensitivity slopes, $r=$ $-.53, p=.02$ (see Figure 1), but not to sweet liking slopes, $r=.12, p=.62$, or sweet liker vs. sweet disliker classifications, $r=0.09, p=.70$. Similarly, AQ total scores were also negatively correlated with sweet sensitivity slopes, $r=-.49 p=.03$ (see Figure 2), but not with sweet liking slopes, $r=-.03, p=.92$, or classifications, $r=-.001, p=.99$. These results indicate that slopes representing decreased sweet sensitivity were associated with increased ASD severity, while hedonic responses to sweet taste (as measured by slopes or categorical classifications) were unrelated to ASD symptoms. 


\section{Discussion}

The current study found no differences between adults with and without ASD with respect to sweet sensitivity or hedonic response to sweet tastes (measured by both sweet liking slopes and dichotomous classification sof "sweet likers" vs. "sweet dislikers"). The lack of between-group differences for sweet taste liking, a primary reward, stands in contrast to the growing literature on reward processing deficits in ASD during the presentation of secondary rewards, including visual images of monetary and social rewards (Dichter, Richey, et al., 2012; Schmitz et al., 2008; Scott-Van Zeeland, Dapretto, Ghahremani, Poldrack, \& Bookheimer, 2010) and images of food (Cascio et al., 2012). The present findings suggest that responses to this particular primary reward may be relatively intact in ASD despite impaired responses to secondary rewards.

While there is accumulating evidence implicating dopaminergic-oxytocinergic brain circuitry in the reward processing deficits of ASD (Kohls et al., 2012), the present results may suggest relative sparing of opioid systems in ASD with regards to hedonic response to sweet taste. These results are also consistent with findings of no atypicalities in peripheral markers of opioid levels in ASD (Cass et al., 2008; Hunter, O'Hare, Herron, Fisher, \& Jones, 2003). In addition, opioids are known to be involved in sustaining a reward approach behavior that has already been initiated (Frisina \& Sclafani, 2002), and ASD is characterized by more prominent deficits in initiating behaviors (Bramham et al., 2009; Garfin \& Lord, 1986) rather than maintaining behaviors (Landa, 2000; Wing, 1997). We also found preliminary evidence of relations between sweet sensitivity and ASD symptom severity as indexed by the SRS and AQ. Because individual differences in sweet sensitivity have been found to be unrelated to opioid functioning (Arbisi et al., 1999; Frisina \& Sclafani, 2002; Hetherington et al., 1991; O'Hare et al., 1997; Yeomans \& Gray, 1996), these results further suggest that opioid dysfunction is not likely implicated in relations between sweet sensitivity and ASD symptoms. However, due to the exploratory nature of the correlational analyses, these results should be interpreted with caution until replicated.

Limitations of the current study include differences in age between the ASD and control groups, although analyses including age as a covariate yielded similar results. In addition, all STT and symptom measures were based on self-report, and ASD is characterized by limited insight into internal states (Silani et al., 2008). There are also limitations inherent in using labeled scales to measure sweet sensitivity and liking across groups, since this approach assumes that the minima and maxima labels (e.g., "not sweet at all" and "extremely sweet") have the same meaning across all individuals and that these meanings are not systematically different between groups (Bartoshuk, 2000; Bartoshuk et al., 2003). Although the current study attempted to address this issue by examining slope rather than raw score ratings, future research should investigate responses to sweet tastes in relation to other sensory responses that are presumably unrelated to taste ratings and are not likely to be systematically different between ASD and control groups (e.g., ratings of a simple auditory or visual stimulus). Finally, it is important to emphasize that this study examined only an indirect marker of opioid functioning, so further research is needed to understand the role of brain opioids in ASD.

In summary, we found that individuals with ASD did not differ in STT hedonic responses, a putative indicator of brain opioid functioning, despite relations between sweet sensitivity and ASD severity. More broadly, these findings contribute to the evolving literature on reward processing deficits in ASD by constraining patterns of deficits to exclude responses to sweet tastes. In addition, given that STT responses predict responses to treatments that impact the opioid system (e.g., naltrexone; Garbutt et al., 2009; Laaksonen, Lahti, Sinclair, 
Heinälä, \& Alho, 2011), future research should evaluate the utility of the STT in predicting responses to opioid-related treatment in ASD.

\section{Acknowledgments}

This research was supported by MH073402, MH081285, Foundation of Hope for the Research and Treatment of Mental Illness, a Dennis Weatherstone Predoctoral Fellowship from Autism Speaks \#7413, and Earl and Barbara Baughman Dissertation Research Award through the Department of Psychology at the University of North Carolina at Chapel Hill. Assistance for this study was provided by the Participant Registry Core of the Carolina Institute for Developmental Disabilities (P30 HD03110). Most importantly, we gratefully acknowledge the participation of individuals with ASD and their families in this research.

\section{Abbreviations}

$\begin{array}{ll}\text { ASD } & \text { autism spectrum disorders } \\ \text { STT } & \text { sweet taste test } \\ \text { ADOS } & \text { Autism Diagnostic Observation Schedule } \\ \text { WASI } & \text { Wechsler Abbreviated Scale of Intelligence } \\ \text { SRS } & \text { Social Responsiveness Scale } \\ \text { AQ } & \text { Autism Spectrum Quotient questionnaire }\end{array}$

\section{References}

APA. Diagnostic and Statistical Manual of Mental Disorders: DSM-V. 5th ed.. American Psychiatric Association; Washington, DC: 2013.

Arbisi P, Billington C, Levine A. The effect of naltrexone on taste detection and recognition threshold. Appetite. 1999; 32(2):241-249. [PubMed: 10097028]

Barbano MF, Cador M. Opioids for hedonic experience and dopamine to get ready for it. Psychopharmacology. 2007; 191(3):497-506. [PubMed: 17031710]

Baron-Cohen S, Wheelwright S, Skinner R, Martin J, Clubley E. The autism-spectrum quotient (AQ): Evidence from asperger syndrome/high-functioning autism, males and females, scientists and mathematicians. Journal of Autism and Developmental Disorders. 2001; 31(1):5-17. [PubMed: 11439754]

Bartoshuk LM. Comparing sensory experiences across individuals: Recent psychophysical advances illuminate genetic variation in taste perception. Chemical Senses. 2000; 25(4):447-460. [PubMed: 10944509]

Bartoshuk LM, Duffy VB, Fast K, Green BG, Prutkin J, Snyder DJ. Labeled scales (e.g., category, Likert, VAS) and invalid across-group comparisons: What we have learned from genetic variation in taste. Food Quality and Preference. 2003; 14(2):125-138.

Bennetto L, Kuschner ES, Hyman SL. Olfaction and taste processing in autism. Biological Psychiatry. 2007; 62(9):1015-1021. [PubMed: 17572391]

Berridge KC, Kringelbach ML. Building a neuroscience of pleasure and well-being. Psychology of Well-Being. 2011; 1(1):1-26. [PubMed: 22328976]

Berridge KC, Robinson TE. What is the role of dopamine in reward: Hedonic impact, reward learning, or incentive salience? Brain Research Reviews. 1998; 28(3):309-369. [PubMed: 9858756]

Berridge KC, Robinson TE. Parsing reward. Trends in Neurosciences. 2003; 26(9):507-513. [PubMed: 12948663]

Bölte S, Poustka F, Constantino JN. Assessing autistic traits: cross-cultural validation of the social responsiveness scale (SRS). Autism Research. 2008; 1(6):354-363. [PubMed: 19360690]

Bramham J, Ambery F, Young S, Morris R, Russell A, Xenitidis K, Murphy D. Executive functioning differences between adults with attention deficit hyperactivity disorder and autistic spectrum 
disorder in initiation, planning and strategy formation. Autism. 2009; 13(3):245-264. [PubMed: 19369387]

Calcagnetti DJ, Reid LD. Morphine and acceptability of putative reinforcers. Pharmacology Biochemistry and Behavior. 1983; 18(4):567-569.

Cascio CJ, Foss-Feig JH, Heacock JL, Newsom CR, Cowan RL, Benningfield MM, Cao A. Response of neural reward regions to food cues in autism spectrum disorders. Journal of Neurodevelopmental Disorders. 2012; 4(9)

Cass H, Gringras P, March J, McKendrick I, O'Hare AE, Owen L, Pollin C. Absence of urinary opioid peptides in children with autism. Archives of Disease in Childhood. 2008; 93(9):745-750. [PubMed: 18337276]

Cohen J. Eta-squared and partial eta-squared in communication science. Human Communication Research. 1973; 28(473-490):56.

Constantino JN, Davis SA, Todd RD, Schindler MK, Gross MM, Brophy SL, Reich W. Validation of a brief quantitative measure of autistic traits: Comparison of the social responsiveness scale with the autism diagnostic interview-revised. Journal of Autism and Developmental Disorders. 2003; 33(4): 427-433. [PubMed: 12959421]

Constantino JN, Przybeck T, Friesen D, Todd RD. Reciprocal social behavior in children with and without pervasive developmental disorders. Journal of Developmental and Behavioral Pediatrics. 2000; 21:2-11. [PubMed: 10706343]

Damiano CR, Aloi J, Treadway M, Bodfish JW, Dichter GS. Adults with autism spectrum disorders exhibit decreased sensitivity to reward parameters when making effort-based decisions. Journal of Neurodevelopmental Disorders. 2012; 4(1):13. [PubMed: 22958545]

Dawson G, Toth K, Abbott R, Osterling J, Munson J, Estes A, Liaw J. Early social attention impairments in autism: Social orienting, joint attention, and attention to distress. Developmental Psychology. 2004; 40(2):271-282. [PubMed: 14979766]

Dawson G, Webb SJ, McPartland J. Understanding the nature of face processing impairment in autism: Insights from behavioral and electrophysiological studies. Developmental Neuropsychology. 2005; 27(3):403-424. [PubMed: 15843104]

Delmonte S, Balsters JH, McGrath J, Fitzgerald J, Brennan S, Fagan AJ, Gallagher L. Social and monetary reward processing in autism spectrum disorders. Molecular Autism. 2012; 3(1):7. [PubMed: 23014171]

Dichter GS, Damiano CA, Allen JA. Reward circuitry dysfunction in psychiatric and neurodevelopmental disorders and genetic syndromes: Animal models and clinical findings. Journal of Neurodevelopmental Disorders. 2012; 4:19. [PubMed: 22958744]

Dichter GS, Richey JA, Rittenberg AM, Sabatino A, Bodfish JW. Reward circuitry function in autism during face anticipation and outcomes. Journal of Autism and Developmental Disorders. 2012; 42(2):147-160. [PubMed: 22187105]

Dichter GS, Smoski MJ, Kampov-Polevoy AB, Gallop R, Garbutt JC. Unipolar depression does not moderate responses to the Sweet Taste Test. Depression and Anxiety. 2010; 27(9):859-863. [PubMed: 20336799]

Frisina PG, Sclafani A. Naltrexone suppresses the late but not early licking response to a palatable sweet solution: Opioid hedonic hypothesis reconsidered. Pharmacology Biochemistry and Behavior. 2002; 74(1):163-172.

Garbutt JC, Osborne M, Gallop R, Barkenbus J, Grace K, Cody M, Kampov-Polevoy AB. Sweet liking phenotype, alcohol craving and response to naltrexone treatment in alcohol dependence. Alcohol and Alcoholism. 2009; 44(3):293-300. [PubMed: 19189996]

Garfin DG, Lord C. Communication as a social problem in autism. Social Behavior in Autism. 1986:237-261.

Greenfield SF, Trucco EM, McHugh RK, Lincoln M, Gallop RJ. The women's recovery group study: A stage I trial of women-focused group therapy for substance use disorders versus mixed-gender group drug counseling. Drug and Alcohol Dependence. 2007; 90(1):39-47. [PubMed: 17446014]

Grelotti DJ, Gauthier I, Schultz RT. Social interest and the development of cortical face specialization: What autism teaches us about face processing. Developmental Psychobiology. 2002; 40(3):213225. [PubMed: 11891634] 
Hajnal A, Norgren R. Taste pathways that mediate accumbens dopamine release by sapid sucrose. Physiology \& Behavior. 2005; 84(3):363-369. [PubMed: 15763573]

Hetherington M, Vervaet N, Blass E, Rolls BJ. Failure of naltrexone to affect the pleasantness or intake of food. Pharmacology Biochemistry and Behavior. 1991; 40(1):185-190.

Hoekstra RA, Bartels M, Cath DC, Boomsma DI. Factor structure, reliability and criterion validity of the Autism-Spectrum Quotient (AQ): A study in Dutch population and patient groups. Journal of Autism and Developmental Disorders. 2008; 38(8):1555-1566. [PubMed: 18302013]

Hunter L, O'Hare A, Herron W, Fisher L, Jones G. Opioid peptides and dipeptidyl peptidase in autism. Developmental Medicine \& Child Neurology. 2003; 45(02):121-128. [PubMed: 12578238]

Kampov-Polevoy AB, Alterman A, Khalitov E, Garbutt JC. Sweet preference predicts mood altering effect of and impaired control over eating sweet foods. Eating Behaviors. 2006; 7(3):181-187. [PubMed: 16843219]

Kampov-Polevoy AB, Eick C, Boland G, Khalitov E, Crews FT. Sweet liking, novelty seeking, and gender predict alcoholic status. Alcoholism, Clinical and Experimental Research. 2004; 28(9): 1291-1298.

Kampov-Polevoy AB, Eick C, Boland G, Khalitov E, Crews FT. Sweet liking, novelty seeking, and gender predict alcoholic status. Alcoholism: Clinical and Experimental Research. 2006; 28(9): 1291-1298.

Kampov-Polevoy AB, Garbutt JC, Davis CE, Janowsky DS. Preference for higher sugar concentrations and Tridimensional Personality Questionnaire scores in alcoholic and nonalcoholic men. Alcoholism: Clinical and Experimental Research. 2006; 22(3):610-614.

Kampov-Polevoy AB, Garbutt JC, Khalitov E. Family history of alcoholism and response to sweets. Alcoholism: Clinical and Experimental Research. 2003; 27(11):1743-1749.

Kampov-Polevoy AB, Tsoi MV, Zvartau EE, Neznanov NG, Khalitov E. Sweet liking and family history of alcoholism in hospitalized alcoholic and non-alcoholic patients. Alcohol and Alcoholism. 2001; 36(2):165-170. [PubMed: 11259214]

Kampov-Polevoy AB, Ziedonis D, Steinberg ML, Pinsky I, Krejci J, Eick C, Crews FT. Association between sweet preference and paternal history of alcoholism in psychiatric and substance abuse patients. Alcoholism: Clinical and Experimental Research. 2006; 27(12):1929-1936.

Keskitalo K, Knaapila A, Kallela M, Palotie A, Wessman M, Sammalisto S, Perola M. Sweet taste preferences are partly genetically determined: Identification of a trait locus on chromosome 16. American Journal of Clinical Nutrition. 2007; 86(1):55-63. [PubMed: 17616763]

Kohls G, Chevallier C, Troiani V, Schultz RT. Social 'wanting'dysfunction in autism: neurobiological underpinnings and treatment implications. Journal of Neurodevelopmental Disorders. 2012; 4(10): 1-20. [PubMed: 22958445]

Kosar E, Grill HJ, Norgren R. Gustatory cortex in the rat. I. Physiological properties and cytoarchitecture. Brain Research. 1986; 379(2):329-341. [PubMed: 3742225]

Krahn D, Grossman J, Henk H, Mussey M, Crosby R, Gosnell B. Sweet intake, sweet-liking, urges to eat, and weight change: Relationship to alcohol dependence and abstinence. Addictive Behaviors. 2006; 31(4):622-631. [PubMed: 15990241]

Kringelbach ML, Berridge KC. Towards a functional neuroanatomy of pleasure and happiness. Trends in Cognitive Sciences. 2009; 13(11):479-487. [PubMed: 19782634]

Kurita H, Koyama T, Osada H. Autism-Spectrum Quotient-Japanese version and its short forms for screening normally intelligent persons with pervasive developmental disorders. Psychiatry and Clinical Neurosciences. 2005; 59(4):490-496. [PubMed: 16048456]

Laaksonen E, Lahti J, Sinclair J, Heinälä P, Alho H. Predictors for the efficacy of naltrexone treatment in alcohol dependence: Sweet preference. Alcohol and Alcoholism. 2011; 46(3):308-311. [PubMed: 21266377]

Landa R. Social language use in Asperger syndrome and high-functioning autism. Asperger Syndrome. 2000:125-155.

Lange LA, Kampov-Polevoy AB, Garbutt JC. Sweet liking and high novelty seeking: Independent phenotypes associated with alcohol-related problems. Alcohol and Alcoholism. 2010; 45(5):431436. [PubMed: 20663854] 
Leventhal L, Bodnar RJ. Different central opioid receptor subtype antagonists modify maltose dextrin and deprivation-induced water intake in sham feeding and sham drinking rats. Brain Research. 1996; 741(1):300-308. [PubMed: 9001736]

Looy H, Weingarten HP. Effects of metabolic state on sweet taste reactivity in humans depend on underlying hedonic response profile. Chemical Senses. 1991; 16(2):123-130.

Lord C, Risi S, Lambrecht L, Cook EH, Leventhal BL, DiLavore PC, Rutter M. The Autism Diagnostic Observation Schedule-Generic: A standard measure of social and communication deficits associated with the spectrum of autism. Journal of Autism and Developmental Disorders. 2000; 30(3):205-223. [PubMed: 11055457]

Mennella JA, Pepino MY, Reed DR. Genetic and environmental determinants of bitter perception and sweet preferences. Pediatrics. 2005; 115(2):e216-e222. [PubMed: 15687429]

Miller A, Barr RG, Young SN. The cold pressor test in children: Methodological aspects and the analgesic effect of intraoral sucrose. Pain. 1994; 56(2):175-183. [PubMed: 8008408]

O'Hare E, Cleary J, Weldon D, Billington C, Levine A, Bartz P. Naloxone administration following operant training of sucrose/water discrimination in the rat. Psychopharmacology. 1997; 129(3): 289-294. [PubMed: 9084069]

Pecina S, Berridge KC. Hedonic hot spot in nucleus accumbens shell: Where do mu-opioids cause increased hedonic impact of sweetness? Journal of Neuroscience. 2005; 25(50):11777-11786. [PubMed: 16354936]

Pecina S, Smith KS, Berridge KC. Hedonic hot spots in the brain. Neuroscientist. 2006; 12(6):500511. [PubMed: 17079516]

Pepino MY, Mennella JA. Sucrose-induced analgesia is related to sweet preferences in children but not adults. Pain. 2005; 119(1):210-218. [PubMed: 16298489]

Reilly S, Grigson PS, Norgren R. Parabrachial nucleus lesions and conditioned taste aversion: Evidence supporting an associative deficit. Behavioral Neuroscience. 1993; 107(6):1005. [PubMed: 8136054]

Rosenthal JA. Qualitative descriptors of strength of association and effect size. Journal of Social Service Research. 1996; 21:37-59.

Schmitz N, Rubia K, van Amelsvoort T, Daly E, Smith A, Murphy DGM. Neural correlates of reward in autism. The British Journal of Psychiatry. 2008; 192(1):19-19. [PubMed: 18174503]

Scott-Van Zeeland AA, Dapretto M, Ghahremani DG, Poldrack RA, Bookheimer SY. Reward processing in autism. Autism Research. 2010; 3(2):53-67. [PubMed: 20437601]

Silani G, Bird G, Brindley R, Singer T, Frith C, Frith U. Levels of emotional awareness and autism: An fMRI study. Social Neuroscience. 2008; 3(2):97-112. [PubMed: 18633852]

Smith KS, Berridge KC. Opioid limbic circuit for reward: Interaction between hedonic hotspots of nucleus accumbens and ventral pallidum. Journal of Neuroscience. 2007; 27(7):1594-1605. [PubMed: 17301168]

Thompson DA, Moskowitz HR, Campbell RG. Effects of body weight and food intake on pleasantness ratings for a sweet stimulus. Journal of Applied Physiology. 1976; 41(1):77-83. [PubMed: 972136]

Wechsler, D. Wechsler abbreviated scale of intelligence. The Psychological Corporation: Harcourt Brace \& Company; New York, NY: 1999.

Wing L. Asperger's Syndrome: management requires diagnosis. Journal of Forensic Psychiatry. 1997; 8(2):253-257.

Wronski M, Skrok-Wolska D, Samochowiec J, Ziolkowski M, Swiecicki L, Bienkowski P, Scinska A. Perceived intensity and pleasantness of sucrose taste in male alcoholics. Alcohol and Alcoholism. 2007; 42(2):75-79. [PubMed: 17267440]

Yeomans MR, Gray RW. Selective effects of naltrexone on food pleasantness and intake. Physiology \& Behavior. 1996; 60(2):439-446. [PubMed: 8840904] 


\section{Highlights}

- Sweet taste sensitivity and liking were compared in ASD versus controls.

- No between-group differences were found for sweet sensitivity or liking slopes.

- No between-group differences were found for a categorical measure of sweet liking.

- ASD symptoms were negatively correlated with sweet sensitivity but not liking. 


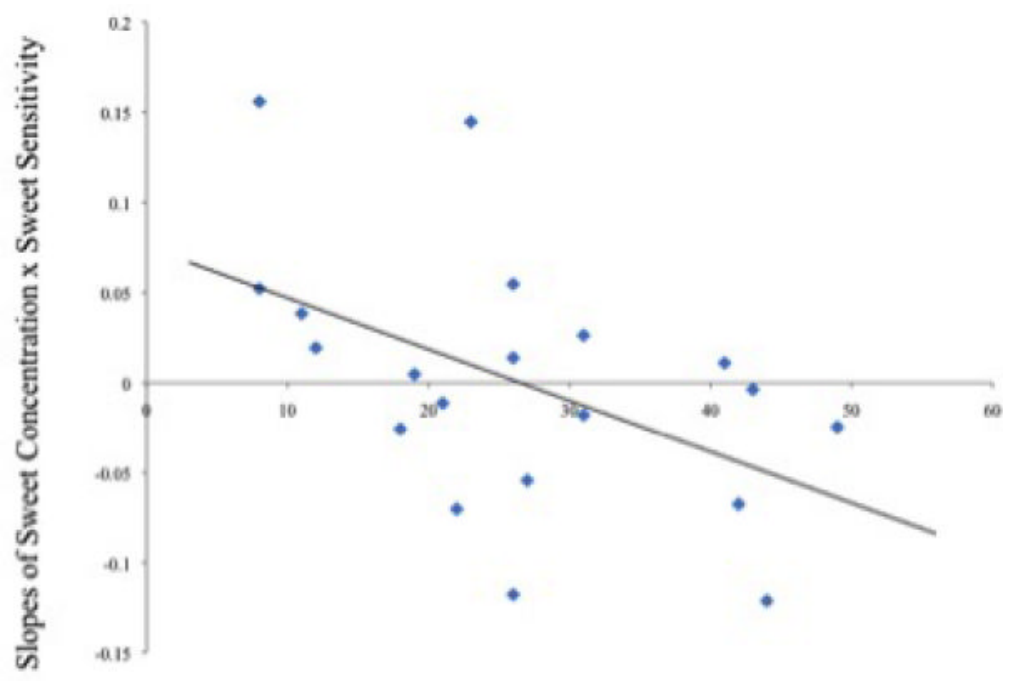

Total Scores on the AQ

Figure 1.

Scatterplot of the relation between the slopes of natural logarithm transformed values for sweet concentration $\times$ sweet sensitivity from the Sweet Taste Test (STT) and total scores for the Autism Spectrum Quotient (AQ) in the ASD group. 


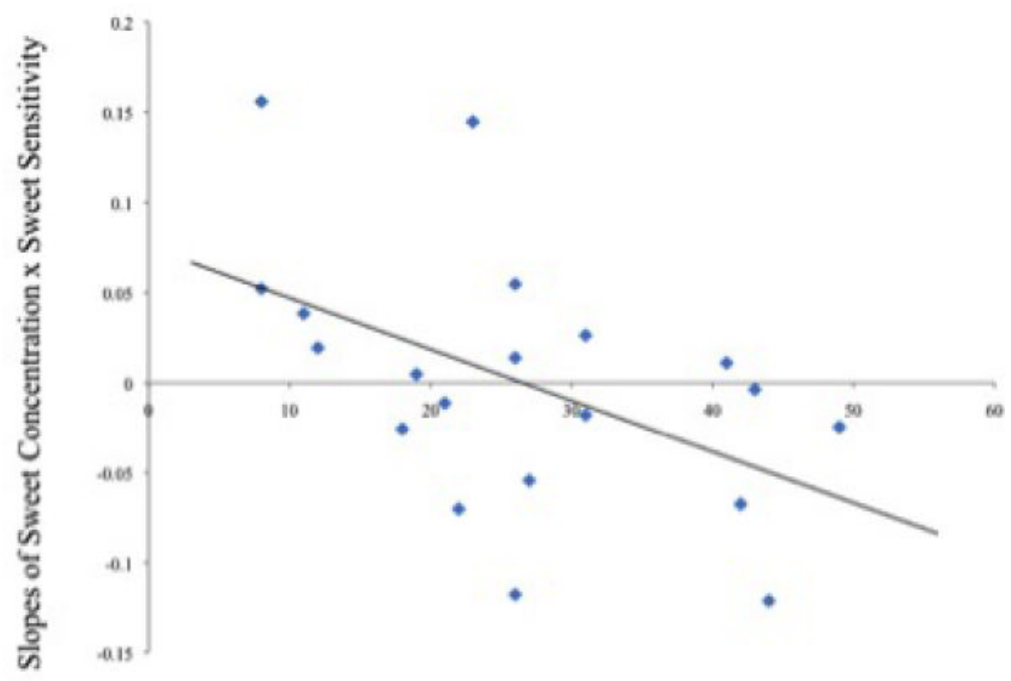

Total Scores on the AQ

Figure 2.

Scatterplot of the relation between the slopes of natural logarithm transformed values for sweet concentration $\times$ sweet sensitivity from the Sweet Taste Test (STT) and total standardized scores from the Social Responsiveness Scale (SRS) in the ASD group. 


\section{Table 1}

Means and Standard Deviations for Participant Characteristics in the ASD and Control Groups

\begin{tabular}{lllll}
\hline & ASD Mean (SD) & Control Mean (SD) & $\boldsymbol{t} / \chi^{2}$ & $p$ \\
\hline Age & $25.95(7.96)$ & $20.42(5.64)$ & 2.764 & .01 \\
Verbal IQ & $112.50(14.65)$ & $112.94(9.94)$ & -0.135 & .89 \\
Performance IQ & $113.60(10.39)$ & $109.17(9.06)$ & 1.664 & .10 \\
Full scale IQ & $114.70(11.25)$ & $112.82(8.66)$ & 0.709 & .48 \\
Male: female & $17: 3$ & $34: 4$ & 0.247 & .62 \\
Autism Spectrum Quotient (total score) & $26.40(12.36)$ & $14.35(5.99)$ & 5.02 & $<.0001$ \\
Autism Spectrum Quotient (range) & $8-49$ & $7-29$ & & \\
Social Responsiveness Scale (t-score) & $68.20(14.37)$ & $55.49(9.31)$ & 4.08 & $<.0001$ \\
Social Responsiveness Scale (range) & $40-90$ & $39-73$ & & \\
\hline
\end{tabular}




\section{Table 2}

Means and Standard Deviations for Natural Logarithm Transformed Slopes and Average Raw Score Ratings in Sweet Sensitivity and Sweet Liking for the Sweet Taste Test (STT) in the ASD and Control Groups, and ANOVA Results for the Main Effect of Group.

\begin{tabular}{lllll}
\hline & $\underline{\text { ASD }}$ Mean (SD) & $\underline{\text { Control Mean (SD) }}$ & $\underline{\boldsymbol{F}}$ & $\underline{\underline{p}}$ \\
\hline Sweet sensitivity & & & & \\
$\quad$ Slope & $2.49(1.24)$ & $2.35(1.07)$ & $\underline{0.09}$ & $\underline{.77}$ \\
$\quad$ Average raw rating & $94.05(22.74)$ & $96.81(16.35)$ & $\underline{0.28}$ & $\underline{.60}$ \\
$\quad \begin{array}{l}\text { Sweet liking } \\
\quad \text { Slope }\end{array}$ & $0.13(1.33)$ & $0.34(1.30)$ & $\underline{1.09}$ & $\underline{.30}$ \\
$\quad$ Average raw rating & $104.96(25.96)$ & $104.51(20.93)$ & $\underline{0.006}$ & $\underline{.94}$ \\
\hline
\end{tabular}

